\title{
Innovation platform approach and food legumes value-chain improvement in Abda and Ahmar regions, Morocco
}

\author{
Basma OKBI, Jamila AMZILE
}

\begin{abstract}
Morocco has been experiencing during the last decade innovating approaches to improve its agricultural productivity while adopting an ascending territorial and value-chain development approaches. Among the multi-actors approaches, that are undergoing the adoption process to reach this purpose in a limited scale, is the Innovation Platform (IP) approach which is being tested on the value-chain of "Food Legumes" that are undergoing a rehabilitation initiative at the national level in the main production areas. The objectives of this work are: to present briefly this experience and to examine its possible impact on governance and sustainable use of different resources. This IP is a coalition of stakeholders who meet to share their experiences, knowledge, skills, resources and ideas for the purpose of solving problems and seize opportunities of common interest. It includes collaborators from various social and economic actors and institutions that govern their behavior, all working toward a common goal. They serve as a mechanism to improve communication, coordination and the sharing of knowledge between the key players on the India-Morocco Food Legume Initiative (IMFLI) project sites. This IP is serving also as a tool for dialog between the different actors of the value-chain to identify collectively the challenges and find opportunities to improve the food legumes production and marketing by the adoption of better technologies and innovations. The platform has adopted innovation as a systemic and dynamic process of institutional learning and recognizes that innovation can emerge from several sources, of complex interactions and knowledge flows. In our IP case the innovation consists of 3 main traits: the technology could be a commodity, a crop type, a variety, a race or integrated management of crops, water or soil packages; organizational in terms to organize and disseminate the knowledge of new ways; and institutional in terms of rules, cultures, values, norms, behavior, policy and laws. This concept of innovation systems embraces not only the providers of science but the totality and the interactions of the actors involved in innovation to achieve a common goal.
\end{abstract}

Index Terms - innovation platform, stakeholder, food legumes, sustainable, agriculture

\section{INTRODUCTION}

Sustainable agricultural development is one of the priorities of the National Agricultural Plan (Green Morocco Plan) to face the main challenges such as: food security, climate change impacts, sustainable efficient- use of natural resources (water, soil, biodiversity, and population growth and transformation). The traditional approach of agricultural research and extension follows a linear approach where researchers and experts produce new knowledge and

OKBI Basma, Agri-food and Health Laboratory, Faculty of Sciences and Techniques, University Hassan $1^{\text {st }}$, Settat. Morocco, +212666845042

AMZILE Jamila, Agri-food and Health Laboratory, Faculty of Sciences and Techniques, University Hassan $1^{\text {st }}$, Settat. Morocco. technology and transfer it to the end users who need it to innovate and change [1]. The research and extension institutions are considered to be the only source of knowledge and innovation required to promote agricultural development and most of the time we found out that research isn't linked to technology users and other actors in the sector [2]. Morocco has been experiencing during the last decade innovating approaches to improve its agricultural productivity while adopting an ascending territorial and value chain development approaches. Among the multi-actors approaches, that are undergoing the adoption process to reach this purpose in a limited scale, find the Innovation Platforms (IP) approach that is based on the integration of value-chains, Agricultural research organizations, local farmers' involvement beside other local actors, and local and national policy makers. IP's are increasingly seen as a promising vehicle for agricultural innovation in developing countries [3], [4], [5], [6], [7], [8], [9]. The innovation systems approach is a more holistic approach to planning knowledge production and use [2]. The innovation systems framework sees innovation in a more systematic, interactive and evolutionary way, whereby networks or organizations, together with the institutions and policies that influence their innovative behaviors and performance, bring new products and processes into economic and social use [10]. Indeed, this IP approach is being tested on the "Food Legumes" value-chain that is undergoing a rehabilitation initiative at the national level in the main production basins.

The objectives of this work are: to present briefly this experience and to examine its possible impacts on governance and sustainable use of different resources.

\section{THE COMMON BASIS OF THE CREATED INNOVATION PLATFORM UNDER STUDY}

This Innovation Platform is based around value-chain which is characterized by: a product, a market, function (or technical operations), actors, forms of relations/exchanges/contracts between the actors, and specific territories or production basins. "Food legumes" are agricultural value-chains of traditional type controlled by operations of cash market implying a large number of small producers.

In our case we will designate the Food Legumes innovation platforms by "IMFLI-IP" (India Morocco Food Legumes Initiative - Innovation platform). The "IP-IMFLI" aims the grouping of means to the open local farmers communities and resources users, enabling them to carry out their Research and Development and innovation projects, in order to improve and stabilize food, the grain food legumes and farmers incomes. It is imperative, therefore, to consider that it is more 
practiced in each area of Morocco and to ensure a sustainable management of their cropping systems.

Beyond the "business as usual", the usual triad of peasant (farmers), extension and research institutions involved in these two programs of agricultural development, the innovation platforms reach a broad group of stakeholders. In this sense, the innovation platforms addressed the problems of actors and take advantage of the opportunities created by the "IMILA" and "ROSFPB" projects. These PI will stimulate the interactions and therefore the innovations in a manner that befits the needs and realities of local actors and will constitute a space of negotiation, planning, working and mutual learning. At this level the goals and objectives should be limited, precise and clear for everyone. These IP's will be by their nature, dynamic and flexible.

\section{THE FOOD Legume VALUE CHAIN "IMFLI-IP"}

\section{A. Innovation Platform at different hierarchical levels}

The IMFLI IP's are established at different hierarchical levels, from ten local operational IP as the case of the two IP's of Abda and Ahmar areas, five regional or sub-national IP's and one overall national IP. These IP's are located at different levels; they have different specific objectives and exercising functions. The local IP's are more focused on the empowerments of local stakeholders and communities to

- Analyze their own constraints and weaknesses and also their opportunities and strength

- To reinforce their capacities to innovate through a better access and use of new knowledge and information that will improve the enterprises performances ,

- They are oriented on mutual learning for a better integrated crop management of food legumes.

The regional and national IP's play an important role in the overall coordination, the identification and the solution to the institutional and political constraints and the increased internal and external best practices and lessons learned.

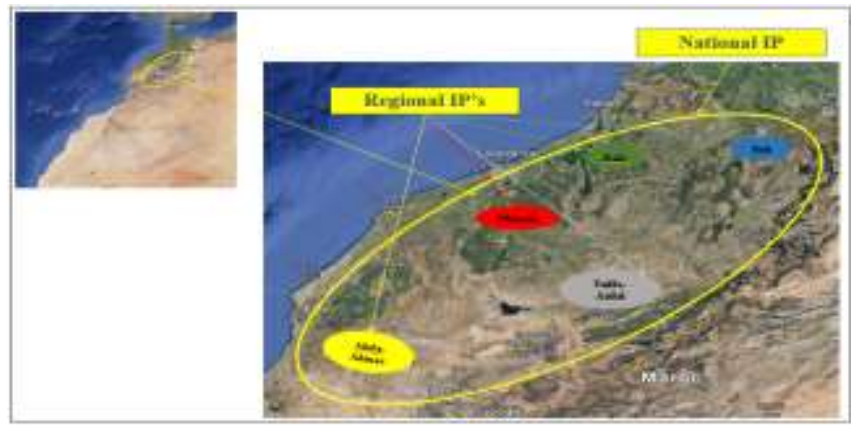

Fig a: Localization of the five regional IP's within the national IP-IMFLI

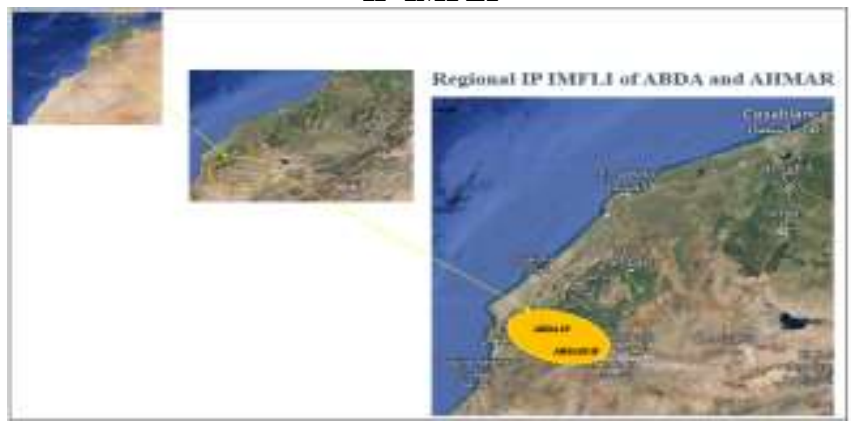

Fig b: The example of the two local IP's of Abda and Ahmar

Fig 1: Different hierarchical levels, from the local IP's (operational IP), Regional and National

\section{B. Main Innovation Platforms Stakeholders}

Seven groups of stakeholders gathering more than 30 actors are involved at each level of the IMFLI-IP. These groups are represented in the following table.

Table: IMFLI-IP stakeholders and examples of actors involved in the food legume value-chain

\begin{tabular}{|c|c|}
\hline Stakeholders & Actors \\
\hline Research & $\begin{array}{l}\text { - INRA: National Institute of Agronomic } \\
\text { Research the project leader } \\
\text { - IAV: Hassan II Agronomy and } \\
\text { Veterinary Institute, Rabat } \\
\text { - ICARDA: International Center for } \\
\text { Agricultural Research in the Dry } \\
\text { Areas } \\
\text { - Universities of Settat, Casablanca, } \\
\text { Rabat, El Jadida, Meknes, Fes and } \\
\text { Beni Mellal } \\
\end{array}$ \\
\hline $\begin{array}{l}\text { Agricultural development } \\
\& \text { policy making }\end{array}$ & $\begin{array}{l}\text { - DRA: Regional Direction of } \\
\text { Agriculture } \\
\text { - DPA: Provincial Direction of } \\
\text { Agriculture } \\
\text { - ONSSA: National Office for the safety } \\
\text { of food products } \\
\end{array}$ \\
\hline $\begin{array}{l}\text { Extension, training and } \\
\text { monitoring }\end{array}$ & $\begin{array}{l}\text { ONCA: National office for agricultural } \\
\text { advise (extension) } \\
\text { - CT: Extension offices } \\
\text { - ONG: Non-Governmental } \\
\text { organizations } \\
\text { - INDH: National Initiative for human } \\
\text { development }\end{array}$ \\
\hline $\begin{array}{l}\text { Development facilitators } \\
\text { and funding }\end{array}$ & $\begin{array}{l}\text { - Regional and local authorities } \\
\text { representing the ministry of interior: } \\
\text { Willayas, local authorities, regional, } \\
\text { provincial and rural councils } \\
\text { - OCP: Cherifian office of Phosphates } \\
\text { - OCP F: The foundation of Cherifian } \\
\text { Office of Phosphates }\end{array}$ \\
\hline Input & $\begin{array}{l}\text { SONACOS: National seed marketing } \\
\text { company }\end{array}$ \\
\hline $\begin{array}{l}\text { Commerce and } \\
\text { valorization }\end{array}$ & $\begin{array}{l}\text { - ONICL: National Inter-professional } \\
\text { Office for Cereals and Legumes } \\
\text { - CAM: Moroccan Agricultural } \\
\text { Cooperatives } \\
\end{array}$ \\
\hline Farmer & $\begin{array}{l}\text { The local farmers organizations, } \\
\text { associations and/or cooperatives }\end{array}$ \\
\hline
\end{tabular}

The figure 2 shows the main stakeholders who are involved in the IMFLI-IP food legumes value chain; we can notice that all the stakeholders are working in collaboration together

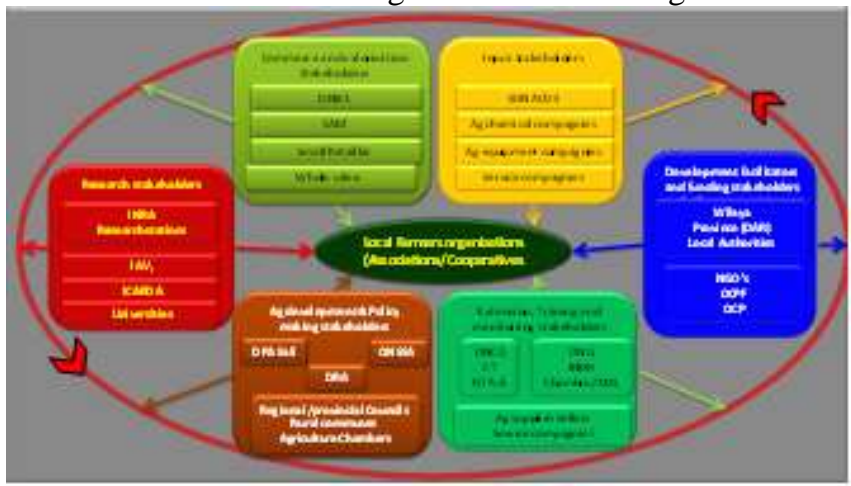

Fig 2: The main stakeholders involved in the IMFLI-IP food legumes value-chain in Morocco.

\section{STRUCTURE OF IP IN LOCAL LEVEL}

A local coordination committee is designated to plan, validate, and insure the follow up of all actions planned during the growing season. Three kind of actions are carried out each year (Fig. 3) those related the chain-value, other related the sustainable use of available natural resources 
(integrated crop management and other accompanying actions (farmers field schools, field days, trainings, communication, and so on). It is important that the results of actions should be reported at regular meetings to remedy the constraints or exploit new possibilities to improve the performance of value chains value and/or the management of natural resources. The frequency of meetings of the IMFLI-IP is 2 or 3 times per year or according to the needs.

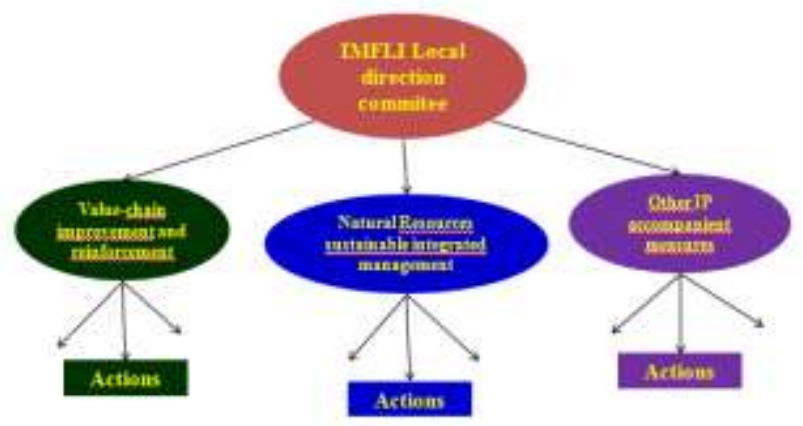

Fig.3: Structure of the local IMFLI-IP

\section{MANAGEMENT OF THE PARTNERSHIP AND THE} APPROPRIATION PROCESS BY LOCAL ACTORS AND FARMER

\section{COMMUNITIES}

The effective partnerships management is crucial, therefore the facilitation of IP meetings, the monitoring of activities between meetings, as well as the establishment and management of relations between the stakeholders must be done in a manner that is frequent, regular and continuous. Knowing that the facilitation is essential for the success of the IP's functioning process, the research organization (INRA) is in charge of this task in a first phase. Initially, the staff of the project that belongs to this institution are playing a leadership role in the facilitation and meeting management of the IP stakeholders. However, over time (2 to 3 years) the local institutions should be encouraged and strengthened in order to support this role to ensure the value-chain of IMFLI-IP sustainability and to ensure its sustainable financing and functions.

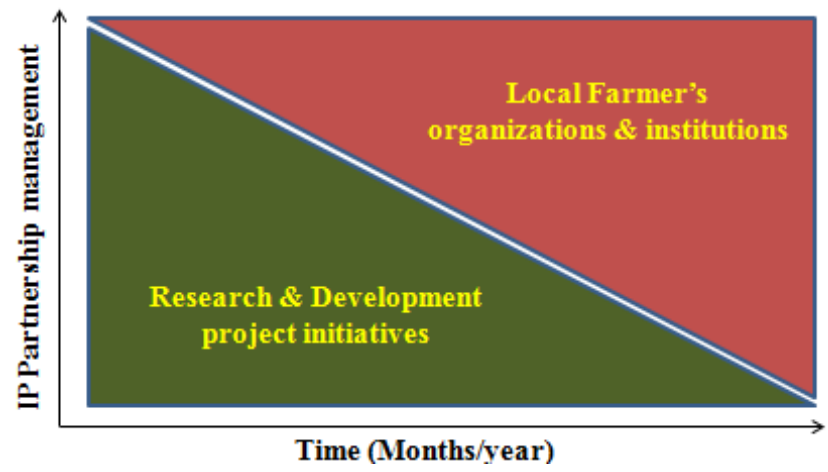

Fig. 4: The appropriation process by local actors and farmer communities of IP-IMFLI

Sufficient attention should be paid to reflecting on the IP process of learning and adaptive management [11], [4]. In that way, IPs can provide a space where expectations and tensions related to transition processes, approaches to innovation, and the new roles and tasks for different stakeholders (including for research and researchers) can be discussed and negotiated [12]. This joint reconsideration and restructuring has been found essential for collective action and agricultural innovation [13]. To support such reflection, more documentation that is rigorous and analysis of IP processes are needed, using systematic approaches as [14] have done for participatory research. This can lead to better understanding about the key features that influence platform performance in a given context [15].

\section{CONCLUSION}

This IP under adoption in Morocco is a coalition of stakeholders who meet to share their experiences, knowledge, skills, resources and ideas for the purpose of solving problems and seize opportunities of common interest. It includes collaborators from various social and economic stakeholders and institutions that govern their behavior, all working toward a common goal. They serve as a mechanism to improve communication, coordination and the sharing of knowledge between the key players on the IMFLI project sites. This IP is serving also as a tool for dialog between the different stakeholders of the value-chain to identify collectively the challenges and find opportunities to improve the food legumes production and marketing by the adoption of better technologies and innovations. The platform has adopted innovation as a systemic and dynamic process of institutional learning and recognizes that innovation can emerge from several sources, of complex interactions and knowledge flows.

In our IP case the innovation consists of 3 main traits:

a) The technology could be a commodity, a crop type, a variety or integrated management of crops, water or soil packages

b) Organizational in terms to organize and disseminate the knowledge of new ways; and

c) Institutional in terms of rules, cultures, values, norms, behavior, policy and laws.

This concept of innovation systems embraces not only the providers of science but the totality and the interactions of the stakeholders involved in innovation to achieve a common goal.

\section{ACKNOWLEDGMENT}

The authors are very thankful to the INRA specially the Regional Center for Agronomic Research of Settat and all the stakeholders who are involved into the IMFLI Project, for giving us the opportunity to write this paper that is the result of mutual collaboration between our university and the other institutes.

\section{REFERENCES}

[1] Lundy, Mark, Maria V. Gottret, and Jacqueline Ashby. 2007. "Learning Alliances: An approach for Building Multi-Stakeholder Innovation Systems " Pp. 37-57 in Learning Alliances: Scaling up Innovations in Water, Sanitation and Hygiene, edited by S.Smits, P. Moriarty, and C. Sijbesma. Delft, The Netherlands: IRC International Water and Sanitation Centre. (Technical paper series; no. 47).

[2] World Bank. 2007. Enhancing Agricultural Innovation: How to Go Beyond the Strengthening of Research Systems. Washington, DC: The International Bank for Reconstruction and Development / The World Bank.

[3] Adekunle, A. A. and Fatunbi, A. O. (2012). Approaches for setting-up multi-stakeholder platforms for agricultural research and development. World Applied Sciences Journal 16(7):981-988.

[4] Kilelu, C. W., Klerkx, L. and Leeuwis, C. (2013). Unravelling the role of innovation platforms in supporting coevolution of innovation: 
contributions and tensions in a smallholder dairy development programme. Agricultural Systems 118:65-77.

[5] Ngwenya, H. and Hagmann, J. (2011). Making innovation systems work in practice: experiences in integrating innovation, social learning and knowledge in innovation platforms. Knowledge Management for Development Journal 7(1):109-124

[6] Pamuk, H., Bulte, E. and Adekunle, A. A. (2014). Do decentralized innovation systems promote agricultural technology adoptiono Experimental evidence from Africa. Food Policy 44:227-236

[7] Swaans, K., Boogaard, B., Bendapudi, R., Taye, H., Hendrickx, S. and Klerkx, L. (2014). Operationalizing inclusive innovation: lessons from innovation platforms in livestock value chains in India and Mozambique. Innovation and Development 4(2):239-257.

[8] van Mierlo, B. and Totin, E. (2014). Between script and improvisation: institutional conditions and their local operation. Outlook on Agriculture 43(3):157-163.

[9] van Paassen, A., Klerkx, L., Adu-Acheampong, R., Adjei-Nsiah, S. and Zannoue, E. (2014). Agricultural innovation platforms in West Africa. How does strategic institutional entrepreneurship unfold in different value chain contexts? Outlook on Agriculture 43(3):193-200.

[10] Hall, Andy. 2005. "Capacity Development for Agricultural Biotechnology in Developing Countries: An Innovation Systems View of What it is and How to Develop it " Journal of International Development 17:611-630

[11] Arkesteijn, M., van Mierlo, B. and Leeuwis, C. (2015). The need for reflexive evaluation approaches in development cooperation. Evaluation 21(1):99-115.

[12] Schut, M., Leeuwis, C., van Paassen, A. and Lerner, A. (2011). Knowledge and innovation management in the policy debate on biofuel sustainability in Mozambique: what roles for researchers? Knowledge Management for Development Journal 7(1):45-64

[13] Wellbrock, W., Roep, D., Mahon, M., Kairyte, E., Nienaber, B. Domínguez García, M. D., Kriszan, M. and Farrell, M. (2013). Arranging public support to unfold collaborative modes of governance in rural areas. Journal of Rural Studies 32(0):420-429.

[14] Neef, A. and Neubert, D. (2011). Stakeholder participation in agricultural research projects: a conceptual framework for reflection and decision-making. Agriculture and Human Values 28(2):179-194

[15] Schut, M., Klerkx, L., Sartas, M., Lamers, D., Campbell, M., Ogbonna, I., Leeuwis, C. (2016). Innovation platforms: experiences with their institutional embedding in agricultural research for development. Experimental Agriculture, 52(4), 537-561. DOI:10.1017/S001447971500023X 